\title{
ESTUDOS DE NARRATIVAS SOBRE MEMÓRIAS DE ALFABETIZAÇÃO: ALGUMAS CONSIDERAÇÕES SOBRE LETRAMENTO E NUMERAMENTO
}

\author{
Maira Bartira Kaufmann ${ }^{1}$ \\ Graziela Rodrigues Lucas ${ }^{2}$ \\ Maria Eduarda de Melo Silveira ${ }^{3}$ \\ Cláudio José de Oliveira ${ }^{4}$ \\ Felipe Gustsack ${ }^{5}$
}

\section{RESUMO}

Apresentamos, a partir do presente artigo, alguns dos resultados parciais do projeto de pesquisa "Linguagem e Educação Matemática para a Educação Básica: um estudo de experiências pedagógicas", que tem como objetivo geral estudar a formação de professores e suas experiências pedagógicas nas escolas de Educação Básica. O referencial teórico está concebido, principalmente, a partir dos estudos de Jorge Larrosa, Angela Kleiman e Maria Celeste Souza em relação aos conceitos de narrativa, letramento e numeramento, respectivamente. A produção e discussão de dados, por sua vez, se deu a partir de encontros quinzenais com o grupo da pesquisa, constituído por acadêmicos de cursos da graduação da UNISC, por mestrandos do PPGEdu/UNISC e por professores da rede pública estadual de ensino. Para a escrita deste texto, entretanto, consideramos as narrativas de dez professores participantes do Pacto Nacional pela Alfabetização na Idade Certa - PNAIC, acerca de suas memórias de alfabetização, buscando compreender de que forma os conceitos de letramento e numeramento eram apresentados nos enunciados. A partir da análise do material, percebemos que o processo de alfabetização demonstra um distanciamento dos campos da vida social, estando muito mais associado ao ensino de práticas e à aprendizagem de habilidades individuais de escrita e leitura.

Palavras-chave: Narrativas. Letramento. Numeramento. PNAIC.

\begin{abstract}
Here, from this article, some of the partial results of the research project "Language and Mathematics Education for Basic Education: a study of teaching experience", which has as main objective to study the formation of teachers and their teaching experience in schools Basic Education. The theoretical framework is designed mainly from Jorge Larrosa studies, Angela Kleiman and Maria Celeste Souza in relation to narrative concepts, literacy and numeracy, respectively. The production and discussion of data, in turn, took from fortnightly meetings with the research group consisting of undergraduate academic courses UNISC, by masters of PPGEDU/UNISC and teachers from the state public school system. For the writing of this text, however, consider the narratives of ten participants teachers of the National Pact

\footnotetext{
1 Aluna do Curso de Pedagogia da Universidade de Santa Cruz do Sul (UNISC). <mairakaufmann@hotmail.com>.

${ }^{2}$ Aluna do Curso de Psicologia da Universidade de Santa Cruz do Sul (UNISC). <glucas@mx2.unisc.br>.

${ }^{3}$ Aluna do Curso de Matemática da Universidade de Santa Cruz do Sul (UNISC).

<dudamelosilveira@hotmail.com>.

4 Professor do Departamento de Educação na Universidade de Santa Cruz do Sul - UNISC. <coliveir@unisc.br>.

${ }^{5}$ Professor do Departamento de Educação e no Programa de Pós-Graduação em Educação na Universidade de Santa Cruz do Sul (UNISC). <fegus@unisc.br>.
} 
for Literacy in the Age One - PNAIC about their literacy memories, trying to understand how the concepts of literacy and numeracy were presented in the statements. From the analysis of the material, we realized that the process of literacy demonstrates a distance from the fields of social life, which one is more associated with teaching practices and learning of individual writing and reading skills.

Keywords: Narratives. Literacy. Numeracy. PNAIC.

\section{INTRODUÇÃO}

Nosso trabalho apresenta alguns dos resultados obtidos durante o primeiro semestre de execução (fevereiro a julho de 2014) do projeto de pesquisa "Linguagem e Educação Matemática para a Educação Básica: um estudo de experiências pedagógicas”, o qual está vinculado ao Programa de Pós-Graduação em Educação da Universidade de Santa Cruz do Sul - UNISC.

O interessante, e também maior desafio do nosso projeto, é que ele foi pensado, desde sua origem, como uma ação integrada de duas Linhas de Pesquisa: a "Identidade e Diferença na Educação" e a "Aprendizagem, Tecnologias e Linguagens na Educação". A investigação teve por objetivo geral estudar a formação de professores e suas experiências pedagógicas nas escolas de Educação Básica - EB, enfocando os processos envolvidos nas atividades de Linguagem e de Educação Matemática. O grupo da pesquisa, por sua vez, é constituído por acadêmicos dos Cursos de Pedagogia, Matemática e Psicologia da UNISC, por mestrandos do PPGEdu/UNISC e por professores da rede pública estadual de ensino. Na escrita deste texto, no entanto, discutimos a forma como professores que participam do Pacto Nacional pela Alfabetização na Idade Certa - PNAIC narram as suas memórias de alfabetização, no que tange as questões de letramento e numeramento.

O PNAIC ou Pacto é uma política pública, fruto da união entre governo federal, estados, municípios e instituições, criada no ano de 2012 com o intuito de assegurar que todas as crianças estejam alfabetizadas até os oito anos de idade, ao final do $3^{\circ}$ ano do ensino fundamental. Suas ações se apoiam em quatro eixos de atuação: 1) Formação continuada presencial para os professores alfabetizadores e seus orientadores de estudo; 2) Materiais didáticos, obras literárias, obras de apoio pedagógico, jogos e tecnologias educacionais; 3) Avaliações sistemáticas; 4) Gestão, mobilização e controle social.

O Pacto é a expressão de uma das atuais prioridades nacionais, ou seja, a alfabetização. Este programa considera que o professor alfabetizador tem a função de auxiliar na formação para o bom exercício da cidadania, e que "para isso, não basta ser um bom 
reprodutor de métodos que objetivem apenas o domínio de um código básico. É preciso ter clareza sobre qual concepção de alfabetização está subjacente à sua prática” (BRASIL, 2015). E é pensando também nos processos de alfabetização, bem como na formação docente, que neste trabalho buscamos compreender de que forma os conceitos de letramento e numeramento aparecem nas narrativas de professores do Pacto.

\section{FUNDAMENTAÇÃO TEÓRICA}

As discussões propostas neste artigo fundamentam-se, principalmente, nas problematizações de três conceitos do estudo, isto é, narrativa, letramento e numeramento. Dessa forma, a partir da investigação e articulação desses conceitos, conseguimos dar um ponto de partida ao trabalho analítico que pretendíamos empreender.

No que tange o conceito de narrativa, nos aproximamos da definição proposta por Larrosa (1995). Para o autor, a narrativa nada mais é que uma forma de caracterizar os fenômenos da experiência humana. Uma vez que nós, seres humanos, somos organismos contadores de histórias, ele diz que o estudo da narrativa é, portanto, o estudo da forma como os seres humanos experimentam o mundo. Na mesma direção de Larrosa, Clandinin e Connelly (apud MARQUESIN; PASSOS, 2009), também entendem a narrativa como uma forma de compreensão da experiência e apropriação de saberes. Para os autores, são histórias humanas que atribuem sentido, importância e propósito às práticas, resultando, nesse sentido, da interpretação e significação de quem está falando ou escrevendo.

Para pensar as questões do letramento, consideramos principalmente as contribuições feitas por Kleiman (2007). Para a autora, o letramento tem como objeto de reflexão os aspectos sociais da língua escrita. Assim, quando falamos em alfabetização, por exemplo, é necessário se levar em conta uma concepção social da escrita, o que difere de uma concepção tradicional que considera a aprendizagem de leitura e produção textual como algo ligado apenas à aprendizagem de habilidades individuais. Um bom planejamento das aulas, nesse sentido, seria aquele que partisse da bagagem cultural diversificada dos alunos e não daquilo que é considerado a sequência mais adequada para a apresentação dos conteúdos, ou seja, "[as] letras para formarem sílabas, [as] sílabas para formarem palavras e [as] palavras para formarem frases" (2007, p. 1).

Ainda segundo Kleiman (2007), a diferença entre ensinar uma prática e ensinar o aluno a desenvolver uma competência e/ou habilidade não é tão simplória. O ambiente escolar, pois, é marcado predominantemente por uma concepção do 'ler' e do 'escrever' como 
um conjunto de habilidades que são progressivamente desenvolvidas até o indivíduo atingir um nível ideal de proficiência na língua escrita. Os estudos do letramento, em contrapartida, partem de uma concepção de leitura e de escrita como práticas discursivas, que possuem múltiplas funções e estão imbricadas aos contextos nas quais se desenvolvem.

Para discutir o conceito de numeramento, por sua vez, nos aproximamos das problematizações feitas a partir do Grupo de Estudos sobre Numeramento da Universidade Federal de Minas Gerais (GEN/UFMG), em especial, dos estudos desenvolvidos por Fonseca (2007) e Souza (2011). Em sua tese de doutorado, Souza (2008) explica que a criação do termo numeramento se deu a partir da preocupação de vários pesquisadores, entre eles Gelsa Knijnik e Maria da Conceição Fonseca, em conhecer e explicar as relações entre leitura, escrita e matemática, bem como compreender os modos culturais de se fazer matemática nos diversos campos da vida social, de modo a percebê-los com base em suas intenções, condições e repercussões. O numeramento, nesse contexto, distancia-se do conceito de alfabetização matemática - entendida como a aquisição da linguagem matemática formal e de registro escrito -, tendo em vista que busca

investigar como tais relações e modos de matematicar são produzidos por (e produzem) modos de "ser" crianças, adolescentes, pessoas jovens e adultas com marcadores sociais diversos (étnicos, geracionais, de classe, de gênero etc.) em suas relações com a matemática (SOUZA, 2008, p. 48).

Deste modo, buscamos refletir sobre as narrativas dos professores com base nas discussões realizadas acerca desses conceitos. Neste sentido, numerar não se restringe ao ver o mundo pelos números, mas agir e pensar o que nos rodeia, pensando matematicamente. Em outras palavras, é entender que a matemática é muito mais que resolver as 'contas escolares' a partir do algoritmo sugerido pelo professor em sala de aula.

\section{METODOLOGIA}

Nosso projeto de pesquisa tem como base a metodologia da Pesquisa-ação, o que nos possibilita avanços no diálogo e contribui para uma maior interação entre todos os envolvidos na pesquisa. Barbier (2007) concebe a Pesquisa-ação como uma forma de pesquisa na qual há uma ação deliberada de transformação da realidade. Nesse sentido, tem como objetivos transformar a realidade e produzir conhecimentos relativos a essas transformações. Para o autor, nesse tipo de metodologia não se trabalha sobre os outros, e sim com os outros, o que exige que o pesquisador seja mais que um especialista: "ela o convida a ser verdadeiramente, 
e talvez, tão simplesmente, um ser humano" (KRISHNAMURTI apud BARBIER, 2007, p. $15)$.

A geração dos dados se deu a partir da realização de debates em rodas de conversa, salas de bate-papo e fóruns (presenciais e virtuais). Os encontros foram realizados quinzenalmente, onde organizamos e refletimos acerca do material teórico de referência, bem como sobre o material empírico. Durante os encontros do grupo da pesquisa, realizamos discussões acerca das narrativas de dez professores da rede pública estadual de ensino, as quais são participantes do PNAIC. Essas narrativas nos foram disponibilizadas pela coordenadora do programa no município de Candelária ${ }^{6}$, cuja qual é uma das participantes do grupo da pesquisa. É importante ressaltar que essas narrativas não foram pensadas inicialmente como material de nosso estudo. No entanto, foram produzidas a partir de uma atividade desenvolvida em um dos encontros do programa, configurando-se, assim, um material relevante para nossa proposta investigativa.

Os conceitos que balizaram a escrita deste texto foram estudados, principalmente, a partir dos seguintes textos: "Sobre a adoção do conceito de numeramento no desenvolvimento de pesquisas e práticas pedagógicas na educação matemática de jovens e adultos", da autora Maria da Conceição Ferreira Reis Fonseca (2007); “Tensões entre oralidade e escrita nas práticas de numeramento de alunas e alunos da EJA: a escrita como mecanismo de diferenciação nas relações de gênero e matemática”, da autora Maria Celeste Reis Fernandes de Souza (2011); e "O conceito de letramento e suas implicações para a alfabetização", da autora Angela B. Kleiman (2007).

\section{RESULTADOS}

$\mathrm{Na}$ análise do material de pesquisa, percebemos que as narrativas dos professores sobre suas memórias de alfabetização seguiram linhas de pensamento distintas: três delas falaram sobre as suas memórias enquanto alunas, três narraram sobre suas memórias enquanto alfabetizadoras e quatro delas narraram sobre ambas experiências. Apesar disso, as narrativas apontaram certas regularidades em seus enunciados, a saber: ênfase na figura do professor; referência ao uso de materiais didáticos; sentimento de insegurança diante do desafio de alfabetizar; a noção de experiência como algo que se adquire com o tempo; a representação da escola como um lugar encantado; bem como concepções de letramento e numeramento. No entanto, considerando o enfoque dado na pesquisa, optamos neste texto por aprofundar nossa

\footnotetext{
${ }^{6}$ O município de Candelária está localizado na região Centro-Serra do estado do Rio Grande do Sul.
} 
discussão nas questões de letramento e numeramento. Para tal, selecionamos alguns excertos ${ }^{7}$ das narrativas analisadas.

\subsection{Narrativas e letramento}

\footnotetext{
"Enquanto ela não compreender a finalidade das letras, dos sons quando se juntam, das palavras que ela pode formar e para que serve, ela não entende esse universo que é o letramento".

"Recordo que logo ao iniciar o Curso Normal, ainda meninas, conversávamos sobre como seria ensinar cada letra, cada som, fazer o aluno compreender a formação de palavras, tudo isso de forma lúdica e prazerosa".

"Recordo que a gente ia aprendendo uma letra de cada vez... maiúscula e minúscula e depois a cursiva. A professora nos dava o desenho da letra para pintar em folha, e após, a gente fazia o traçado das letras sobre as linhas pontilhadas".
}

Observando o primeiro excerto e relacionando-o com o conceito de letramento que adotamos nesse trabalho, parece-nos que a alfabetização descrita nas narrativas define-se como o ensino de uma prática, uma competência, que se daria a partir do desenvolvimento de certas habilidades, tais como compreender a finalidade das letras, dos sons, das palavras que ela pode formar. Esse seria então um conjunto de habilidades que deveriam ser desenvolvidas progressivamente para se atingir uma competência leitora e escrita ideal. Nesse sentido, podemos perceber que essa prática diferencia-se dos estudos do letramento, isso porque esse conceito configura a leitura e a escrita como praticas discursivas, as quais possuem múltiplas funções e que são inseparáveis dos contextos em que se desenvolvem.

O segundo e terceiro excertos apresentam uma narrativa que vai ao encontro do primeiro, isso porque também nestes é possível perceber que o letramento está descrito como uma prática de ensino/aprendizagem estática, na qual se trabalha cada letra, cada som, fazendo compreender a formação de palavras. No entanto, essa prática na realidade descreve a alfabetização que, segundo Soares (2006, p. 15), é o "processo de aquisição do código escrito, das habilidades de leitura e escrita". Nesta perspectiva, percebe-se nos excertos que o contexto social está dissociado das práticas e que, portanto, as narrativas descrevem práticas de alfabetização e não de letramento.

Para compreender melhor essa afirmação, faz-se necessário que entendamos o campo do letramento como aquele que tem como objeto de reflexão os aspectos sociais da língua

\footnotetext{
${ }^{7}$ Os excertos são apresentados em itálico à margem direita no corpo do texto.
} 
escrita. Deste modo, assumir como finalidade o letramento no contexto escolar implica adotar a alfabetização como uma concepção social da escrita, o que se difere das concepções tradicionais que consideram a aprendizagem da leitura e da escrita como a aprendizagem de habilidades individuais, dissociadas do seu contexto (KLEIMAN, 2007). Podemos sugerir, então, que, por mais que os professores utilizem o termo letramento em suas narrativas, não percebemos uma real apropriação e entendimento deste conceito por parte deles.

\subsection{Narrativas e numeramento}

\footnotetext{
"Não lembro de tudo, mas marcou minha infância essas caminhadas de estudante. [...] Aprendemos os números na sequência em que íamos memorizando, realizando exercícios como fazemos hoje, creio".

"Hoje, como alfabetizadora, ainda não tenho muitas experiências pelo pouco tempo que estou em sala de aula, mas as coisas gratificantes acontecem a todo momento e delas não esquecemos, como um aluno [...] conseguir resolver cálculos ou problemas matemáticos, reconhecer letras e números...”

“Quando eu fui alfabetizada, eu já queria como algumas colegas ser professora, pois adorávamos escrever no quadro, brincar com letrinhas, fazer recorte em jornais, montar palavrinhas, resolver pequenos cálculos”.
}

A análise dos excertos acima nos sugere que a alfabetização matemática é entendida como a aquisição da linguagem matemática formal e do registro escrito. Mendes (2005, p. 01) acredita que “'alfabetização matemática' é referente aos atos de aprender a ler e escrever a linguagem matemática usada nas primeiras séries de escolarização”. Nesse sentido, podemos dizer que essa definição distancia-se do conceito de numeramento, considerando que o mesmo pretende ir além dessa proposta, procurando enfocar os aspectos sociais que envolvem a escrita matemática, incluindo as diversas possibilidades de representação.

Podemos perceber que a matemática apresentada nos três excertos está associada ao conceito de alfabetização matemática, visto que em todas as passagens a mesma está representada a partir da memorização dos números e resolução de cálculos. No trecho “(...) aprendemos os números na sequência em que íamos memorizando (...)”, percebe-se que há a intervenção de quem educa, pois é o professor quem ensina os números. Segundo Silva (2007, p. 10),

a Educação Matemática, enquanto ação entre humanos, caracteriza-se igualmente pela intervenção de um sobre o outro: um que educa, outro que se deixa educar; um que ensina, outro que deseja aprender; um que transmite o conhecimento, outro que se apropria do conhecimento transmitido. 
Deste modo, a análise das narrativas sugere que há uma aproximação da matemática com o conceito de alfabetização matemática, o que configuraria um distanciamento da noção de numeramento por nós adotada. Segundo Fonseca (2007, p. 04),

\begin{abstract}
A ideia de alfabetização, nesse caso é a da iniciação a um campo, e a adjetivação é para que se transfira esse sentido da iniciação mais elementar ao mundo da leitura e da escrita, para, no caso da Alfabetização Matemática, o campo da Aritmética, trilhando os primeiros passos da construção do conceito de número, da aquisição da representação numérica no sistema decimal de numeração, ou da resolução de problemas simples envolvendo as operações fundamentais om Números Naturais; ou ainda para uma primeira incursão no campo da Geometria, contemplando noções topológicas ou reconhecimento e classificação de figuras.
\end{abstract}

Com base nos excertos analisados e estudos sobre numeramento, percebemos que o conceito de matemática para os professores está mais associado à educação matemática, visto que elas se remetem às lembranças de cálculos, problemas e números, sem nenhuma menção às matemáticas culturalmente produzidas.

\title{
5 CONSIDERAÇÕES FINAIS
}

Ao finalizar este texto, é preciso retomar o momento inicial das análises. Muito teremos ainda para pensar, outras lentes teóricas podem ser utilizadas. Deste modo, considerando o objetivo destes escritos, ou seja, discutir a forma como professores que participam do PNAIC narram as suas memórias de alfabetização em relação as questões de letramento e numeramento, nos aventuramos, neste momento, na problematização de alguns achados.

No que se refere aos termos alfabetizar, numerar e alfabetização, usualmente mencionado pelos professores, nos parecem distantes do conceito de numeramento. Estranho, pois, perceber que as crianças em seus primeiros domínios escolares sejam apresentados para uma alfabetização que exclui ou pouco inclui a ideia de matematizar as questões que estão ao seu entorno. Inferir que pensar alfabetização não inclui noções básicas de matemática, remete a própria formação dos professores que ensinam matemática nos Anos Iniciais do Ensino Fundamental. Mesmo não fazendo parte do estofo deste texto, não podemos nos deixar invisível que os próprios cadernos do PNAIC, assim como outros materiais ofertados na formação continuada de professores, reforçam concepções de matemática, como um processo de seguir regras mecânicas, resumindo as experiências matemáticas de professores e alunos ao mundo da escola. 
Em outro sentido, também podemos problematizar os conceitos de letramento, numeramento e outros que circularam por este texto. Tivemos dificuldade em dizer "o que é mesmo", isto ou aquilo. Optamos então em acompanhar Bauman (2012), quando diz: "Não pergunte pelo significado: pergunte pelo uso.” (p. 68). Seguindo o autor, entre as muitas teorias atuais na busca dos significados, ficamos com os sentidos atribuídos nos locais onde aparecem. Deste modo, para concluir, e, ao mesmo tempo, deixar muitas frestas para recomeçar, podemos resumir que, nos achados do estudo, alfabetizar é preciso, matemática não é preciso.

\section{REFERENCIAS}

BARBIER, R. A pesquisa-ação. Trad. Lucie Didio. Brasília: Liber Livro, 2007.

BAUMAN, Z. Ensaios sobre o conceito de cultura. Trad. Carlos Alberto Medeiros. Rio de Janeiro: Zahar, 2012.

BRASIL. Ministério de Educação e Cultura. Entendendo o Pacto. Disponível em: <http://pacto.mec.gov.br/o-pacto $>$. Acesso em: 05 mar. 2015.

FONSECA, M. C. F. R. Sobre a adoção do conceito de numeramento no desenvolvimento de pesquisas e práticas pedagógicas na educação matemática de jovens e adultos. In: IX ENCONTRO NACIONAL DE EDUCAÇÃ̃O MATEMÁTICA, 2007, Belo Horizonte. Anais... Belo Horizonte, 2007, p. 01-12. Disponível em: <http://www.sbembrasil.org.br/files/ix_enem/Html/palestra.html >. Acesso em: 13 dez. 2014.

KLEIMAN, A. B. O conceito de letramento e suas implicações para a alfabetização. Letramento do professor, UNICAMP, p. 01-10, fev. 2007. Disponível: $<$ http://www.letramento.iel.unicamp.br/publicacoes/artigos/Letramento_AngelaKleiman.pdf $>$. Acesso em: 09 mar. 2015.

LARROSA, J. et al. Déjame que te cuente: ensayos sobre narrativa y educación. Barcelona: Laertes, 1995.

MARQUESIN, D. F.; PASSOS, L. F. Narrativa como objeto de estudo: aportes teóricos. Múltiplas Leituras, São Paulo, n. 2, v. 2, p. 219-237, jul./dez. 2009. Disponível em: <https://www.metodista.br/revistas/revistas-ims/index.php/ML/article/viewFile/1450/1475>.

Acesso em: 15 mar. 2015.

MENDES, J. R. Reflexões sobre numeramento: práticas sociais de leitura em torno do conhecimento matemático. In: XV CONGRESSO DE LEITURA DO BRASIL, 2005, Campinas. Anais... São Paulo, 2005, p. 01-09. Disponível em: <http://alb.com.br/arquivomorto/edicoes_anteriores/anais15/alfabetica/ MendesJackelineRodrigues.htm>. Acesso em: 10 mar. 2015.

SILVA, N. M. A. Matemática e educação matemática: re(construção) de sentidos com base na representação social de acadêmicos. In: GT EDUCAÇÃO MATEMÁTICA, 2007, Rio de 
Janeiro. Anais... Rio de Janeiro, 2007, p. 01-12. Disponível em: <http://www.ufrrj.br/emanped/paginas/conteudo_producoes/docs_30/matematica.pdf $>$. Acesso em: 10 mar. 2015.

SOARES, M. Alfabetização e letramento. 4. ed. São Paulo: Contexto, 2006.

SOUZA, M. C. R. F.. Gênero e matemática(s) - jogos de verdade nas práticas de numeramento de alunas e alunos da educação de pessoas jovens e adultas. Belo Horizonte, 2008. 317p. Tese (Doutorado), Programa de Pós-Graduação em Educação, Universidade Federal de Minas Gerais, 2008. Disponível em: $<$ http://www.bibliotecadigital.ufmg.br/dspace/bitstream/handle/1843/FAEC85FNHS/genero_e_matematica.pdf?sequence=1>. Acesso em: 27 fev. 2015.

SOUZA, M. C. R. F.. Tensões entre oralidade e escrita nas práticas de numeramento de alunas e alunos da EJA: a escrita como mecanismo de diferenciação nas relações de gênero e matemática. Educação em Foco, Juiz de Fora, n. 2, v. 16, p. 81-113, set. 2011/ fev. 2012. Disponível em: 〈http://www.ufjf.br/revistaedufoco/files/2012/08/Maria-Celeste.pdf>. Acesso em: 13 dez. 2014. 